\title{
LUCHAS INTERNAS EN LA ZONA FRANQUISTA DURANTE LA GUERRA CIVIL
}

\author{
JOAN MARIA THOMÀS (ICREA / URV) \\ ICREA Academia / Universidad Rovira i Virgili \\ joanmaria.thomas@urv.cat
}

\section{Resumen:}

El presente artículo analiza las tensiones políticas internas producidas en la zona franquista o España "nacional" durante la Guerra Civil española (1936-1939). Partiendo de la diversidad de la coalición autoritaria o bloque político y social de los alzados contra la Segunda República, estudia dicha conflictividad atendiendo a los diferentes proyectos políticos en concurrencia, así como las tensiones entre los dos partidos ultraderechistas dominantes -Falange Española de las JONS (fascista) y Comunión Tradicionalista (carlista) - y el poder franquista. Analiza igualmente la gestación de la unificación imperativa e incautación de los dos partidos citados por el Generalísimo para crear el partido único de su régimen, Falange Española Tradicionalista y de las JONS, así como la de la ley fundamental promulgada durante la contienda, el llamado Fuero del Trabajo.

\section{Palabras clave:}

Guerra Civil Española - Fascismo - Falange - Carlismo - Francisco Franco

\begin{abstract}
:
The present article analyses the internal political tensions produced in the Francoist zone or "Nationalist" Spain during the Spanish Civil War (1936-1939). Based on the diversity of the authoritarian coalition against the Second Republic, it studies such conflicts by attending the different political agendas, as well as the tensions between the two extreme right-wing parties Falange Española de las JONS (Fascist) and Comunión Tradicionalista (Carlist) - and the Francoist power. Furthermore, it also analyzes the gestation of the imperative unification and seizure of the two political parties aforementioned by the Generalisimo in order to create the single-party of his regime, Falange Española Tradicionalista y de las JONS. By last, it studies the conflicts generated during the discussions of the ley fundamental promulgated during the war, the Fuero del Trabajo.
\end{abstract}

\section{Keywords:}

Spanish Civil War - Fascism - Falange - Carlism - Francisco Franco 


\title{
LUCHAS INTERNAS EN LA ZONA FRANQUISTA DURANTE LA GUERRA CIVIL
}

\author{
JOAN MARIA THOMÀS (ICREA / URV)
}

joanmaria.thomas@,urv.cat

Si bien en la ya inmensa historiografía sobre la Guerra Civil española predominan, a la hora de tratar las tensiones políticas que se produjeron dentro de cada uno de los dos bandos enfrentados en la contienda, los estudios dedicados a la zona republicana, en los últimos veinticinco años han ido apareciendo trabajos dedicados a la conflictividad que se dio dentro de la llamada zona "nacional" o franquista. Estos trabajos han contribuido a dar una imagen de la misma menos monolítica y armónica de lo que tradicionalmente se había supuesto e incluyendo temas como el ascenso de Franco al poder; la actuación y estrategias de los partidos políticos ultraderechistas actuantes en la zona franquista en el período anterior a la creación del partido único; la llamada Unificación de dichos partidos de abril de 1937; el funcionamiento interno de la coalición autoritaria o bloque político y social franquista; o los debates que dentro de éste se dieron a la hora de elaborar leyes fundamentales del Nuevo Estado, que nos son ahora mejor conocidos.

Ello no obstante, y a pesar de la mejora en el acceso a archivos públicos, queda aún mucho camino por recorrer. Como queda pendiente la localización y/o acceso a fondos documentales de gran importancia para la investigación, entre ellos los del propio dictador -los que no se encuentran custodiados en la Fundación Nacional Francisco Franco de Madrid o en el Archivo de la Presidencia del Gobierno/Jefatura del Estado-, o los de su concuñado Ramón Serrano Suñer, su máximo consejero político y ministro más poderoso del período 1938-1941, entre otros. Aunque en los últimos años se viene produciendo un saludable goteo de cesiones de fondos documentales pertenecientes a personajes del régimen franquista a archivos públicos o a privados con acceso público, ello no deja de ser, al contrario de lo que ocurre en países anglosajones, una tendencia poco extendida en España. En otros casos, descendientes de personajes relevantes del régimen franquista permiten el acceso a investigadores a los fondos que conservan en sus propios domicilios. En las páginas que siguen y mediante el uso de fuentes documentales como las citadas, reconstruimos los principales conflictos y luchas internas que se dieron en la llamada España Nacional durante la Guerra Civil.

Digamos para empezar que ya durante la conspiración que dio lugar al golpe de Estado de los días 17 a 19 de julio de 1936, el fracaso del cual conllevó el estallido de la Guerra Civil, se habían generado tensiones entre los jefes del movimiento militar y los de las dos principales fuerzas auxiliares civiles que participaban en el mismo, es decir la falangista Falange Española de las Juntas de Ofensiva Nacional-Sindicalistas (JONS) y la monárquica carlista-legitimista Comunión Tradicionalista ${ }^{1}$. Por otra parte, entre los generales golpistas, la muerte el 20 de julio en un

\footnotetext{
${ }^{1}$ Un reciente estado de la cuestión en Muñoz Bolaños, Roberto, "La gran coalición contra el Frente Popular" en González Madrid, Damián; Ortiz Heras, Manuel y Pérez Garzón, Juan Sisinio, La Historia. Lost in Translation? Actas del XIII Congreso de la Asociación Historia Contemporánea, Albacete, Universidad de Castilla La Mancha, 2017. (edición digital). Los monárquicos de ultraderecha se dividían entre los seguidores de la dinastía reinante hasta 1931, la de Alfonso XIII, llamados alfonsinos y los partidarios de la rama disidente, los carlistas, que pretendían que la dinastía
} 
accidente de aviación de José Sanjurjo, su jefe incuestionado, dejó un vacío de liderazgo que hasta dos meses después no se llenaría mediante la elección, en las reuniones del 21 y 28 de septiembre, de otro general, Francisco Franco, ahora como Generalísimo y Jefe del Gobierno del Estado Español (un desliz éste de jefe del gobierno que, por restrictivo, rápidamente se corrigió en Jefe del Estado a secas, represaliándose al autor del mismo ${ }^{3}$ ). Tal elección tampoco estuvo exenta de tensiones, en concreto entre aquellos pocos generales que querían continuar con el mando colegiado existente desde el 24 de julio anterior -la Junta de Defensa Nacional de España- y aquellos otros partidarios del mando único y de que éste recayese en la persona de Franco. De entre estos últimos resultaron decisivos dos generales monárquicos alfonsinos - Alfredo Kindelán y Luis Orgaz ${ }^{4}$ - convencidos de que su candidato era igualmente monárquico de esta tendencia... para gran chasco suyo y de sus correligionarios como comprobarían a partir del fin de la Guerra Civil.

Por su parte, los dirigentes de las dos fuerzas políticas que habían participado en cuánto tales en el golpe -Falange Española de las JONS y Comunión Tradicionalista-, hicieron caso omiso durante los primeros nueve meses de la guerra -aquellos en los que existieron en tanto que partidos independientes- de la prohibición de todo tipo de actuaciones políticas, sindicales y patronales dentro la zona nacional decretada por la Junta de Defensa Nacional ${ }^{5}$. Para hacerlo se ampararon en su actuación militar, miliciana más bien, que les legitimaba tras haberse convertido desde el inicio de la guerra en grandes reclutadoras de voluntarios para sus milicias o unidades combatientes partidarias. Compuestas por unidades tipo compañía o batallón llamadas banderas y centurias falangistas y tercios de requetés carlistas ${ }^{6}$, estas unidades resultaban imprescindibles para al ejército golpista en razón de no haber procedido aún a la llamada de quintas -por considerarlo innecesario al creer en una rápida conquista de Madrid y final de la guerra en cuestión de semanas o de muy pocos meses-. Ambos partidos tenían claro que su contribución a la contienda lo era en tanto que paso necesario no sólo para acabar con la República, la democracia, los partidos y sindicatos de izquierdas y los nacionalismos periféricos -objetivos estos comunes a todos los alzados y no sólo a estas dos organizaciones-, sino también para implantar regímenes políticos que resultasen de la plasmación de sus idearios respectivos: un régimen fascista con la Falange en el poder como partido único; o una monarquía neoabsolutista y ultracatólica con un rey de la dinastía carlista al frente. Eran proyectos muy diferentes e incluso contradictorios aunque con grandes coincidencias en lo negativo, es decir, en aquello que pretendían suprimir y erradicar.

Sin embargo, tanto Falange como la Comunión toparían con la voluntad de Franco y de su entorno político de no dejar sin ocupar ninguna parcela de poder independiente fuera de su control. Y tras el nombramiento del Generalísimo como Jefe del Estado el único que quedaba era el partidario. El camino hacia su incautación duró algo más de medio año y culminó con la

\footnotetext{
legítima era la de los descendientes de Carlos María Isidro, tío de la reina Isabel II -abuela de Alfonso XIII- y opuestos a la derogación d la Ley Sálica que había permitido el acceso de aquella reina al trono.

2 Decreto número 138 de 29 de septiembre de 1936. Boletín Oficial de la Junta de Defensa Nacional de España número 32 de 30 de septiembre de 1936.

3 Viñas, Ángel (ed.), Salamanca, 1936. Memorias del primer "ministro" de Asuntos Exteriores de Franco Francisco Serrat Bonastre, Barcelona, Crítica, 2014, pág. 60.

${ }^{4}$ Kindelán Duany, Alfredo, Mis cuadernos de guerra, Barcelona, Planeta, 1982, segunda edición (la primera edición, censurada, apareció en Madrid en 1945, editada por Plus Ultra); Preston, Paul, Franco, “Caudillo de España” Barcelona, Grijalbo, 1994.

${ }^{5}$ Decreto número 31 de 25 de septiembre de 1936. Boletín de la Junta de Defensa Nacional de España de 28 de septiembre de 1936.

${ }^{6}$ No existe aún una estimación exacta de los efectivos de ambas fuerzas para esta etapa. Para el conjunto de la Guerra Civil y utilizando datos sobre excombatientes, los de las milicias de FE de las JONS y FET y de las JONS habrían sido 207.173 y los carlistas 69.279: Parejo Fernández, J.A.: "De puños y pistolas. Violencia falangista y violencias fascistas", en Ayer, no 88 (2012), p. 143.
} 
llamada Unificación de 19 de abril de 1937. Y su curso estuvo jalonado de incidentes entre el poder dictatorial y las direcciones de los dos partidos.

Primero fue un gravísimo incidente -por vía interpuesta- entre el Generalísimo y el JefeDelegado de la Comunión, Manuel Fal Conde, el máximo dirigente carlista por delegación del "rey" carlista, Javier de Borbón-Parma y Braganza, el cual residía fuera del país. Después, la estricta sujeción de las milicias al ejército vía decreto. Ya principios de 1937 se produjo un incidente con Falange, al no aplicar ésta una directriz de la censura oficial referida a su propia propaganda. Por último, aparecieron fuertes tensiones a caballo de los rumores, pronto convertidos en certezas, de que Franco iba a proceder a una unificación imperativa de los dos partidos para situarse al frente de los mismos. Se promoverían actuaciones tendentes a contrarrestar sus efectos y, en el caso de FE de las JONS, se llegaría a una gravísima crisis, con tiros entre camaradas y con dos muertos. Tanto Falange como la Comunión se esforzarían primero por adelantarse a la fusión, pretendiendo realizarla por su cuenta, aunque sin lograr un acuerdo, llegando divididas al momento de la unificación por decreto. E inmediatamente después de dicha unificación se produciría una nueva crisis, saldada con el procesamiento por la justicia militar de toda una serie de falangistas, encabezados por quién había ejercido como su responsable en tanto que Jefe de la Junta de Mando Provisional, Manuel Hedilla.

El primero de los incidentes citados, el relacionado con Manuel Fal Conde, se produjo el 8 de diciembre de 1936 al crear éste -en nombre del pretendiente al trono Don Javier- y publicarlo en el "Boletín de Orientación Tradicionalista", una escuela de formación de oficiales del requeté y al tiempo regular el procedimiento de ascensos en el seno del mismo. Tal "decreto" carlista, que no implicaba vocación provocadora ninguna o desafío del poder de Franco pero significaba un hito más en la independencia desde la que venía actuando la Comunión, le resultó al Generalísimo absolutamente intolerable. De hecho lo calificaría de "golpe de Estado, delito de traición (...) conducta propia de un anarquista, no de un hombre afecto al Movimiento" tras interpretarlo en tanto que cuestionamiento de su jefatura suprema militar y política. Inmediatamente y por orden suya fue convocado Fal Conde ante el general Dávila, presidente de la Junta Técnica del Estado -el organismo encargado por Franco de la gobernación civil de la zona "nacional" - quién le puso ante la alternativa de, o bien ser procesado en consejo de guerra o bien exiliarse, optando el otro por marchar a Lisboa. Poco después, el 20 de diciembre de 1936 y en la estela de lo sucedido, promulgó el jefe del Estado el decreto conocido como de militarización de las milicias dado que en su virtud eran puestas éstas bajo las órdenes directas del ejército a todos los niveles. Aparte de la cuestión estrictamente operativa, se las sujetaba al Código de Justicia Militar, quedaban limitadas a fuerzas de infantería o de caballería - no pudiendo pues contar con ninguna de artillería o ingenieros-, se las obligaba, en el caso de las actuantes en la retaguardia, a cumplir los procedimientos regulados en la Cartilla de la Guardia Civil en todo lo referido a detenciones o sucesos en los que interviniesen, y -y ahí aparece la consecuencia más inmediata de lo ocurrido con el decreto anterior de Fal Conde- se reservaba en las academias militares creadas para la habilitación de alféreces de campaña (después llamados alféreces provisionales) un determinado número de plazas para que aquellos milicianos falangistas o requetés que reuniesen los requisitos requeridos y fuesen seleccionados pudiesen ingresar en ellas, deviniendo oficiales del ejército. A partir de ese momento pues, no habría más oficiales de milicias por designación del mando falangista o del carlista. Todos serían militares.

Un nuevo incidente entre los partidos ultraderechistas actuantes en la España "Nacional" y las autoridades franquistas lo protagonizarían los falangistas en febrero de 1937 al decidir ignorar una orden explícita de la censura -que dependía de la Delegación de Prensa y Propaganda de la Secretaría

\footnotetext{
${ }^{7}$ Diario del Conde de Rodezno cit. en Tusell, Javier, Franco en la Guerra Civil, Barcelona, Tusquets, 1992, pág. 72.

${ }^{8}$ Orella, José Luis, La formación del Estado nacional durante la Guerra Civil española, Madrid, Actas, 2001.
} 
General del Estado que ocupaba el hermano mayor de Franco, Nicolás- de no permitirles radiar un discurso de su antiguo Jefe Nacional José Antonio Primo de Rivera al cumplirse el primer aniversario de la alocución, del 2 de febrero de 1936 en el Cinema Europa de Madrid. Era un discurso pronunciado durante la campaña electoral de los comicios del día 16 siguiente y que contenía críticas tanto a las izquierdas como a las derechas, al tiempo que proclamaba el objetivo falangista de "desmontar el capitalismo" y hacer su propia revolución nacionalsindicalista. Es decir, fascista. Un discurso en el que se decían cosas como que:

“...el capitalismo liberal desemboca, necesariamente, en el comunismo. No hay más que una manera, profunda y sincera, de evitar que el comunismo llegue: tener el valor de desmontar el capitalismo, desmontarlo por aquellos mismos a quienes favorece, si es que de veras quieren evitar que la revolución comunista se lleve por delante los valores religiosos, espirituales y nacionales de la tradición. Si lo quieren, que nos ayuden a desmontar el capitalismo, a implantar el orden nuevo"9.

La prohibición estaba basada en evitar incomodidades a los sectores derechistas aludidos y para no crear fricciones dentro de la coalición autoritaria franquista, pero el mando falangista ordenó que se repartiese el texto del discurso en forma de panfleto, así como que se difundiera a través de las radios de la Zona Nacional ${ }^{10}$. Y en Burgos y Valladolid los falangistas ocuparon dos de ellas y forzaron su lectura. Ello acabó provocando el procesamiento de los responsables falangistas de ambas provincias -José Andino y Dionisio Ridruejo ${ }^{11}$, respectivamente-, si bien al final se sobreseyeron por intervención de Hedilla cerca de Franco. Para entonces hacía ya tres meses que Primo había sido fusilado en la zona republicana -en Alicante, el 20 de noviembre de $1936^{12}$ - si bien esto último se venía manteniendo en secreto en la España "Nacional" por Falange y las autoridades, presuntamente para no desmoralizar a los combatientes falangistas y a la espera de mayores confirmaciones.

Pero las tensiones fundamentales fueron las relacionadas con la cuestión de la unificación. Con la incautación de los dos partidos por el poder y su subordinación a la jefatura de Franco, que con ella devendría -por autonombramiento- también Jefe Nacional del nuevo partido único de régimen, creado con dicha fusión y nuevas incorporaciones. Las tensiones en el seno de las dos organizaciones y con el Cuartel General del Generalísimo por este asunto comenzaron al tenerse noticias vía rumor de la voluntad del dictador y su entorno político de proceder a una operación de este tipo. Y se encresparon al confirmarse la proximidad de aquella y vía decreto ya en marzo de 1937. Las direcciones falangista y carlista no tenían informaciones concretas sobre el cuándo, el cómo o el tipo de organización resultante de la fusión, pero sí de que ésta iba a producirse y de que la fuerza nueva la dirigiría el propio Caudillo. Tan sólo unos días antes de la publicación del decreto el 19 de abril de 1937 los dirigentes carlistas de Navarra -la región con mayor peso carlista- y los más proclives a pactos fueron informados. Los falangistas no fueron convocados, en parte por la lucha interna desatada entre sus dirigentes en los días anteriores, pero Hedilla sí contaba con alguna información, fruto de su mayor cercanía con Franco ${ }^{13}$.

$\mathrm{Y}$ es que, de hecho, la noticia de que venía una unificación imperativa desde arriba provocó divisiones internas en las direcciones falangista y carlista. En el caso de la primera, verdaderos movimientos tectónicos. La primera reacción de ambas al aparecer los primeros rumores fue la de tratar de controlar el proceso y, sobre todo, de limitar los daños que tal fusión por decreto

\footnotetext{
9 Arriba núm. 31, 6 de febrero de 1936.

${ }^{10}$ García Venero, Maximiano, Falange en la guerra de España. La Unificación y Hedilla, París, Ruedo Ibérico, 1967, págs. 319-320.

11 Ridruejo, Dionisio, Con fuego y con raíces. Casi unas memorias, Barcelona, Planeta, 1976.

${ }^{12}$ Sobre las circunstancias del fusilamiento de José Antonio Primo de Rivera y sobre el mito sobre su persona véase Thomàs, Joan Maria, José Antonio. Realidady mito, Barcelona, Debate, 2017.

13 Archivo de Manuel Hedilla Larrey.
} 
conllevaría. Lo hicieron por la vía de propiciar y negociar su unión voluntaria. Si FE de las JONS y la Comunión Tradicionalista, de motu propio, eran capaces de acordar una fusión pactando dirección, ideario y estrategia de la fuerza resultante, asegurarían su pervivencia, encubierta ahora en la forma de fusión-coordinación de los dos partidos, y probablemente aún más, de sus núcleos dirigentes, preocupados por ser desalojados del poder caso de que la unificación se hiciese por el Generalísimo. A tal efecto celebraron conversaciones en Lisboa y Salamanca en febrero de 1936.

Estas conversaciones acabaron sin resultado ninguno. $\mathrm{Y}$ es que no faltaban razones para ello: el nivel de incompatibilidad entre los dos idearios políticos era muy grande -concepción fascista del Nuevo Estado falangista versus monarquía neoabsolutista ultracatólica; no confesionalidad del Estado versus confesionalidad, etcétera-. Pero lo fueron aún más las pretensiones de cada uno de los partidos de dominar al otro, fuese por la vía falangista de absorción de la Comunión Tradicionalista o por la inversa. Así, en la capital portuguesa y en su entrevista con Fal Conde, el vocal de la Junta de Mando Provisional y jefe territorial de Andalucía Sancho Dávila, planteó un escrito en el que se afirmaba la absorción de la Comunión por Falange:

"La Falange, creadora de un estilo de la España nueva, recibe con honor en sus filas y en sus mandos a los nuevos camaradas (...) El Yugo y las Flechas [escudo falangista], ahora también sobre camisas pardas [carlistas], será el símbolo de la unidad espiritual de España, que empezamos por realizar nosotros mismos y que comunicamos de un modo exclusivo y totalitario al Estado""14.

Aludía igualmente a una instauración monárquica -que no restauración ya que los carlistas no habían reinado nunca, al contrario que los alfonsinos- de una Monarquía Tradicional -palabra clave carlista- pero sólo en tanto que garantía de continuidad de aquello que se consideraba básico: la implantación del Estado nacionalsindicalista. Fal Conde le respondió con otro escrito, redactado por otro notable carlista, Arauz de Robles, en el que pedía la unión voluntaria de las dos fuerzas y la creación de un triunvirato de mando, así como que, una vez que se ganarse rápidamente la guerra, instituir una regencia e instaurar lo más pronto posible una monarquía católica y tradicionalista. También se instauraría el corporativismo y el nacionalsindicalismo pero entendido éste simplemente como nacionalización de los sindicatos y no como un programa económicosocial. Ante ello se produjo una contrapropuesta falangista, que fue la de reafirmarse en la absorción de la Comunión por FE de las JONS y la instauración de la nueva monarquía tradicional. Ello fue contestado por Fal Conde exigiendo el mando de la nueva fuerza unificada por Don Javier. No se llegó a ningún acuerdo. Como tampoco algunas semanas después, en Salamanca, donde persistieron las posiciones encontradas.

Bloqueada -autobloqueada más bien, por ambos lados- la vía de la unión voluntaria, las direcciones de los dos partidos se mostrarían internamente divididas con respecto a la actitud a mantener ante la unificación por decreto que estaba al llegar. En el caso de los carlistas, se manifestaban diferencias notables entre personajes clave de su dirección como el conde de Rodezno -antiguo Jefe-Delegado de la Comunión antes de Fal Conde- y sus correligionarios de la Junta de Navarra -la organización, repetimos, de mayor peso y raigambre de la Comunión- y el exiliado Fal Conde y el "rey" Don Javier. Los dos últimos eran absolutamente reticentes a aceptar una imposición de Franco mientras los navarros eran más flexibles. No era una división nueva, sino expresión de otra más antigua que ya había creado tensiones entre Rodezno y Fal durante la República ${ }^{15}$, al estar el primero mucho más abierto a la colaboración con los alfonsinos y otras fuerzas ultraderechistas y derechistas y ser el segundo más reticente y siempre laborando por mantener la independencia de la Comunión, por supuesto compartiendo ambos la necesidad de derrocar la República. Franco se apoyaría en los primeros y nombraría a Rodezno como vocal de

\footnotetext{
${ }^{14}$ García Venero, Maximiano, Falange en la guerra de España..., op. cit., pág. 113.

15 Blinkhorn, Martin, Carlismo y contrarrevolución en España 1931-1939, Barcelona, Crítica, 1979.
} 
la nueva Junta Política una vez crease el partido único. A él y a otros carlistas navarros les manifestó que pensaba designarle vicepresidente de la nueva fuerza ${ }^{16}$.

En el caso de los falangistas la situación se agravó al mezclarse con la intención del Jefe de la Junta de Mando Provisional Hedilla de acabar con el mando colegiado que había venido dirigiendo el partido desde poco después del inicio de la guerra y convertirse en nuevo Jefe Nacional del mismo. Pretendía acabar con una interinidad en la gestión que, precisamente en relación con el futuro de la organización, estaba resultando cada vez más problemática. Existían de hecho dos tendencias en la cúpula falangista respecto de la unificación. La primera era la de los familiares de José Antonio Primo de Rivera, el fundador y primer Jefe Nacional: su hermana pequeña y delegada de la Sección Femenina, Pilar; un pariente andaluz de la familia, el citado Sancho Dávila; Agustín Aznar, el Jefe de Milicias y novio de una prima de la familia; Rafael Garcerán, antiguo pasante del bufete de abogado de José Antonio Primo; así como otros, no familiares, y jefes de organizaciones regionales del partido como José Moreno, de Navarra, entre otros $^{17}$. Frente a ellos se encontraban el propio Hedilla, antiguo Jefe Provincial de Santander, nombrado como Jefe de la Junta Provisional en razón de no tener territorio sobre el que ejercer su mando -la mayor parte de Cantabria estaba en manos republicanas por entonces- y por considerársele en su momento nada ambicioso y por supuesto nada aspirante al poder total. Estaba éste en minoría dentro de la Junta, contando con el apoyo de José Sáinz -Jefe Territorial de Castilla la Nueva- y, fuera de la misma, el de un grupo de propagandistas entre los que destacaban los periodistas profesionales Víctor de la Serna -hijo de la escritora Concha Espina y propietario y director del diario "Informaciones" de Madrid- y el santanderino Maximiano García Venero; y el de su secretario José Antonio Serrallach, entre otros. A este último grupo debe atribuirse en buena parte la idea de promocionar a Hedilla como nuevo Jefe Nacional, como jefe de un partido fascista altísimamente jerarquizado y ello por la vía estatutaria: convocando al efecto un Consejo Nacional para proceder a la elección.

La cuestión del poder interno falangista se ligaba con la de la unificación en la medida en que Hedilla, a través de sus contactos con Franco y con los consejeros de éste -especialmente con Serrano Suñer ${ }^{18}$, Ladislao López Bassa ${ }^{19}$, Vicente Sergio Orbaneja o Pedro González-Bueno ${ }^{20}$ - se había mostrado más abierto a la fusión que sus oponentes de la Junta de Mando; abierto a una unificación en la que se le habría asegurado que el partido resultante se basaría mucho más, a nivel de ideario y organizativo, en Falange que en la Comunión, como efectivamente ocurrió. Probablemente él mismo había contribuido a ello en sus conversaciones; y más aún, de cara al propio Franco, con algo que le diferenciaba claramente de sus oponentes, como era el respeto y acatamiento de su autoridad. Frente a esta posición más "política" de Hedilla, de esforzarse por conseguir que la unificación fuese favorable a FE de las JONS -aunque sin debatirlo nunca en el seno de Junta de Mando Provisional ${ }^{21}$ - se encontraba la de otros de los miembros de ésta, los Aznar, Garcerán, Dávila y Moreno que recelaban de él y hacían gala de mantener la organización al margen de cualquier maniobra del Caudillo. Es más, Aznar, en algún encuentro con éste le había mostrado evidentes faltas de respeto. De hecho los vocales citados no se recataban de decir a los suyos que en su camino hacia el poder la Falange arrollaría a quien fuese, en referencia

\footnotetext{
16 Acta de la Junta Central Carlista de Guerra de Navarra. Archivo de Manuel Fal Conde.

17 Thomàs, Joan Maria, El Gran Golpe. El "Caso Hedilla” o cómo Franco se quedó con Falange, Barcelona, Debate, 2016.

18 Serrano Suñer, Ramón, Entre Hendaya y Gibraltar, Barcelona, Nauta, 1973.

${ }^{19}$ Serrano Suñer, Ramón, Entre el silencio y la propaganda. La Historia como fue, Barcelona, Planeta, 1977.

${ }^{20}$ González-Bueno y Bocos, Pedro, En una España cambiante. Vivencias y recuerdos de un ministro de Franco, Barcelona, Áltera, 2006.

21 Thomàs, Joan Maria, “Actas de las reuniones de la Junta de Mando Provisional de Falange Española de las JONS celebradas durante el período 5 de diciembre de 1936-30 de marzo de 1937”, en Historia Contemporánea número 7, Universidad del País Vasco, 1992.
} 
directa al Generalísimo. Algo de lo que éste sabía vía servicios de información del Cuartel General. No es pues de extrañar su preferencia por Hedilla.

Como tampoco lo es que, tras convocar al Consejo Nacional en el que pretendía presentar su candidatura como nuevo Jefe Nacional, pero antes de que tal órgano pudiese reunirse, sus oponentes forzasen -el 16 de abril- una reunión de la Junta de Mando Provisional en la que le destituyeron, creando seguidamente para dirigir el partido un triunvirato que constituyeron ellos mismos -Aznar, Dávila, Moreno- designando un nuevo secretario general (Garcerán). Hedilla, tras una aparente aceptación de su destitución y retirada de la reunión, acabaría ordenando la detención de todos ellos, para cumplir lo cual un piquete de milicianos partió hacia los domicilios de los mismos en la noche de ese mismo día, produciéndose un serio enfrentamiento al proceder a detener al primero de todos ellos, Dávila, en la pensión donde se alojaba y defenderse y su escolta violentamente a ello. El resultado fue de dos falangistas muertos, uno por cada lado.

En estos Sucesos de Salamanca ${ }^{22}$-con tal nombre han pasado a la historia- Franco apoyó a Hedilla, desplegando fuerzas militares y de orden público por la ciudad, y encarceló a los oponentes de aquel. Y, tras adelantarse la celebración del Consejo a los días 18 y 19 de abril y ser elegido Hedilla Jefe Nacional, el Caudillo le dio nuevamente su apoyo. Pero sobre todo lo que hizo fue aprovechar los desórdenes falangistas de los días anteriores para promulgar, el día 19 de abril de 1937, el decreto por el que ordenaba la unificación de Falange y el carlismo en un nuevo partido, con él al frente.

El partido único se denominaba casi exactamente igual -Falange Española Tradicionalista y de las JONS - que la anterior Falange -Falange Española de las JONS- y se dotaba de órganos internos Junta Política, Consejo Nacional- calcados de la misma, al tiempo que adoptaba 26 de los 27 Puntos de su programa ${ }^{23}$. Unos meses después, el 4 de agosto, al promulgar un nuevo decreto instituyendo los estatutos internos de la organización se vio que la mímesis era prácticamente absoluta, con un diseño interior también calcado ${ }^{24}$. Habían sido pues exitosas las gestiones de Hedilla al respecto, así como, el interés de Franco y Serrano Suñer por crear un régimen de partido único parecido al de los aliados alemanes e italianos. Y estaban comenzando a hacerlo creando el partido siguiendo el modelo fascista.

A pesar de ello, la relación Franco-Hedilla acabaría mal ya que, tras designársele, en un nuevo decreto $^{25}$, como primer vocal de la nueva Junta Política o Secretariado Político de FET y de las JONS, se negó el santanderino a aceptar el cargo. Incluso cuando todo apuntaba a que el Generalísimo le nombraría después secretario general. Pero ya en la no aceptación de la vocalía topó con la cerrada negativa del otro, que con ello respondía a las acusaciones de sus adversarios de la cúpula de la antigua FE de "haber vendido la Falange a Franco" y de haberlo hecho para beneficiarse personalmente de ello con un cargo. Algo que la designación como vocal parecía corroborar y que se agravaba por el hecho de que ningún otro ex miembro de la Junta de Mando Provisional había sido nombrado.

\footnotetext{
22 García Venero, Maximiano, Falange en la guerra de España..., op cit.; Southworth, Herbert R., Antifalange. Estudio critico de "Falange en la guerra de España. La Unificación y Hedilla" de M. García Venero, París, Ruedo Ibérico, 1967; Thomàs, Joan Maria, Lo que fue la Falange. La Falange y los falangistas de José Antonio. Hedilla y la Unificación. Franco y el fin de la Falange Española de las JONS, Barcelona, Plaza \& Janés, 1999.

${ }^{23}$ Decreto número 255. Boletín del Movimiento de Falange Española Tradicionalista y de las JONS número 1, 5 de mayo de 1937. El Punto no adoptado, el 27, establecía que en el camino de su acceso al poder FE de las JONS pactaría muy poco. Era por tanto poco adecuado para su incorporación dado que el decreto de Unificación ordenaba una fusión con otra fuerza política.

${ }^{24}$ Decreto número 333 de 4 de agosto de 1937, Boletín del Movimiento de Falange Española Tradicionalista y de las JONS número 2, 15 de agosto de 1937.

${ }^{25}$ Decreto número 260 de 22 de abril de 1937, Boletín del Movimiento de Falange Española Tradicionalista y de las JONS número 1, 5 de mayo de 1937.
} 
Con su negativa, aparte de actuar por prurito personal, buscaba Hedilla forzar una negociación con Franco que permitiese nuevas incorporaciones a la Junta de FET y de las JONS. Pero cometió un error descomunal, demostrando ser mucho menos "político" de lo que había parecido. Y, sobre todo, pareciendo a los ojos de Franco como indisciplinado y rebelde. Además, el hecho de que algunos de sus fieles se movilizasen para organizar alguna resistencia a la aplicación del decreto encendió todas las alarmas del Cuartel General, que movilizó a las fuerzas del orden y autoridades militares de toda la España "Nacional" para prevenir movimientos contrarios y procedió a la detención de los emisarios de Hedilla a diferentes provincias. Todo ello, y sin que esté aún hoy en día del todo claro el grado de implicación del ex Jefe de la Junta de Mando Provisional, le acarrearía a él y a algunos de sus próximos procesamientos y condenas. En el caso del santanderino, la de muerte, luego conmutada.

A partir de entonces y recibida claramente la advertencia, los dirigentes falangistas del grupo de los Primo de Rivera se aprestaron a participar en el partido único, siendo Pilar, Aznar, Dávila y otros oponentes de Hedilla ahora promocionados a altos cargos. El muñidor del pacto fue Serrano Suñer, que era antiguo compañero de estudios de José Antonio Primo de Rivera y conocido de la familia. Pero los grandes perjudicados de la opción descaradamente pro-falangista de la nueva FET y de las JONS, serían los carlistas, pronto orillados en el seno de la dirección de la organización.

Tras dotarse de su partido único de tipo fascista -partido que debería de encuadrar a la población adicta, educarla políticamente y actuar como base de masas organizada del régimen y su líder- y sin que existiese en absoluto la intención de otorgarle el poder del Estado o de poner éste al servicio de aquel -lo que habría homologado al régimen franquista con uno propiamente fascista-, quedó clara la voluntad del Caudillo y de sus consejeros políticos por convertirlo en un componente más de la coalición autoritaria. Un bloque político y social diverso en el que se alineaban el ejército, la iglesia católica, los monárquicos alfonsinos y carlistas, muchos ex cedistas, patronos, empresarios, propietarios agrarios y una masa adicta formada por sectores católicos campesinos, sectores de las clases medias rurales y urbanas... así como los propios falangistas. El primer gobierno creado por Franco el 30 de enero de 1938 ya respondió a esta diversidad. Se designó en aplicación de la nueva Ley de Administración Central del Estado ${ }^{26}$-por la que Franco se auto concedía, ahora formalizándola como ley, "la suprema potestad de dictar las normas jurídicas de carácter general", es decir las leyes. Con ella se suprimían los órganos subordinados a Franco existentes hasta entonces -la Junta Técnica del Estado, la Secretaría General del Estado, etcétera- creándose un gobierno en cuanto tal, con ministerios. En la composición del mismo estaban presentes todas las tendencias políticas e institucionales de la España "Nacional": cuatro militares (el general Jordana como Vicepresidente y ministro de Asuntos Exteriores; el general Fidel Dávila como ministro de Defensa; el general Severiano Martínez Anido como ministro de Orden Público; y el teniente coronel de ingenieros de la Armada Suanzes como ministro de Industria y Comercio); tres monárquicos alfonsinos (Pedro Sáinz Rodríguez ministro de Educación Nacional; Andrés Amado, ministro de Hacienda; y Peña Boeuf en Obras Públicas); un carlista (el propio conde de Rodezno, en Justicia); un falangista viejo, camisa vieja, es decir, proveniente de la Falange anterior a la unificación, Raimundo Fernández-Cuesta (Agricultura), que había ocupado la secretaría general de FE de las JONS cuando José Antonio Primo era Jefe Nacional; y dos falangistas nuevos, Pedro González-Bueno, antiguo seguidor de José Calvo Sotelo, el principal líder alfonsino del período 1934-1936, y participante en los contactos con Hedilla, ministro de Organización y Acción Sindical, y el propio Serrano Suñer, ex diputado de la católicocorporativa Confederación Española de Derechas Autónomas (CEDA), la fuerza derechista más importante del período republicano, y miembro de su facción más radicalizada, que se reservó la cartera de Interior. Todos ellos estaban presididos por Franco, al tiempo jefe del gobierno y del

\footnotetext{
${ }^{26}$ Boletin Oficial del Estado de 31 de enero de 1938.
} 
Estado. Por supuesto todos los miembros del gobierno eran formalmente miembros del nuevo partido, pero ello quedaba simplemente en una cuestión de nombre.

El proyecto de Franco y Serrano era el de conceder ciertas cuotas de poder al partido dentro del gobierno, pero, sobre todo, mantenerlo como órgano de encuadramiento, control y movilización - cuando fuese necesaria- de la población adicta, en tanto que fuerza capaz de agrupar la asistencia popular -en palabras del propio Franco- a su régimen. Y es que ni él mismo era un líder fascista ni estaba dispuesto a conceder al partido único fascista la hegemonía dentro del Nuevo Estado. Ésta permanecería siempre en sus manos, repartiendo poder, manteniendo la toma de decisiones en sus manos y en las de su gobierno y nunca, en cuestiones fundamentales, en las del partido. Este tipo de poder y de realidad hace difícil calificar al régimen franquista como propiamente fascista, resultando más adecuado calificarlo en tanto que de tipo fascistizado, es decir, con un claro componente fascista incrustado en su seno -el partido único FET y de las JONS- pero sin que la ideología y las decisiones de éste marcasen decisivamente la toma de decisiones ${ }^{27}$.

Pero que no fuese así no significa que, al menos hasta la llamada Crisis de Mayo de 1941, los falangistas no intentasen revertir la situación, adquiriendo cuotas de poder decisivas en el Estado. Durante la Guerra Civil ello se vio en el último de los escenarios de los enfrentamientos en el interior de la coalición franquista, el tenido durante la discusión en el seno del Consejo Nacional de FET y de las JONS de una amplia declaración de intenciones de contenido social que, a inspiración y semejanza de la Carta del Lavoro fascista italiana de 1927, se pretendía aprobar. Tal declaración, convertida en ley fundamental, se acabó promulgando por Franco el 9 de marzo de 1938 con la denominación de Fuero del Trabajo. En la citada discusión quedó patente hasta qué punto llegaba la heterogeneidad del bloque franquista, así como las dificultades de los fascistas de Falange por imponerse.

Tal intención tenía el borrador presentado por quién había sido nombrado por Franco recientemente secretario general de FET y de las JONS, el también ministro Fernández-Cuesta. También se presentó otro a discusión, por parte del ministro de Organización y Acción Sindical Pedro González-Bueno, más moderado en el tono. Pero ya en el debate previo de los dos proyectos mantenido por el gobierno, el primero de los dos había recibido acerbas críticas del general Martínez Anido, un conservador autoritario famoso por sus actuaciones represivas durante la Dictadura de los años 1923-1930. Sin embargo, las cosas llegarían mucho más lejos al presentarse los dos textos a la sesión del Consejo Nacional. Toparon allí con monárquicos de ambos signos y conservadores, tratando por su parte los viejofalangistas de Fernández-Cuesta de aumentar la radicalidad de su texto ${ }^{28}$. Ante el espectáculo de una discusión tan dura y, sobre todo, ante la imposibilidad de llegar a un acuerdo, se decidió allí mismo que se crease una comisión formada por el propio Fernández-Cuesta y por un exministro de Trabajo de la Dictadura del general Primo de Rivera, Eduardo Aunós, entre otros- para elaborar un nuevo texto. Así se hizo y el 9 de marzo $^{29}$ se aprobó el texto definitivo, con un contenido católico y tradicional claramente superior al de la Carta fascista italiana y menor radicalidad fascista.

Lo primero se manifestaba en las alusiones que el Fuero contenía a la tradición católica, al artesanado ("herencia viva de un glorioso pasado gremial que será fomentado y eficazmente protegido por ser proyección completa de la persona humana en su trabajo y suponer una forma de producción igualmente apartada de la concentración capitalista y del gregarismo marxista"); al pequeño

\footnotetext{
27 Sobre el concepto de fascistización y régimen fascistizado véase Griffin, Roger, The Nature of Fascism, LondresNueva York, Roudletge, 1993; Saz, Ismael, "Tres acotaciones a propósito de los orígenes, desarrollo y crisis del fascismo español”, en Revista de Estudios Políticos, Nueva Época, número 50, 1986; Thomàs, Joan Maria, La Falange de Franco. Fascismo y fascistización en el régimen franquista (1937-1945), Barcelona, Plaza \& Janés, 2001.

28 Martínez de Bedoya, Javier, “El sindicalismo español de 1936 a 1939”, en Revista de Política Social, 1956, pág. 19.

${ }^{29}$ Decreto de promulgación del Fuero del Trabajo de 9 de marzo de 1938, Boletín del Movimiento de Falange Española Tradicionalista y de las JONS de 15 de marzo de 1938.
} 
patrimonio agrícola, pesquero, industrial y comercial; a la familia campesina ("se tenderá a dotar a cada familia campesina de una pequeña parcela, el huerto familiar, que le sirva para atender a sus necesidades elementales y ocupar su actividad en los días de paro"); o a la familia en general ("célula primaria natural y fundamento de la sociedad, y al mismo tiempo (...) institución moral dotada de derecho inalienable y superior a toda ley positiva. Para mayor garantía de su conservación y continuidad se reconocerá el patrimonio familiar inembargable"). Estaban también presentes las aportaciones carlistas en cuestiones como el artesanado y, compartiéndolas con la iglesia, el tono en general catolizante del documento.

Pero también estaban claras las aportaciones fascistas falangistas en aquello referido a la voluntad de mejorar las condiciones de vida de las clases medias y bajas de la población. Y si bien no se habían acabado introduciendo sus alusiones a la necesidad de una reforma económica de la tierra o a la nacionalización de la banca y de algunos servicios públicos -puntos éstos del antiguo programa de FE incorporados por lo demás sin problemas, como hemos visto, en el de FET- sí otros muchos, como la definición del Nuevo Estado en tanto que "instrumento totalitario al servicio de la integridad patria, y sindicalista en cuanto representa una reacción contra el capitalismo liberal y el materialismo marxista que emprende la tarea de realizar -con aire militar, constructivo y gravemente religioso- la Revolución que España tiene pendiente y que ha de devolver a los españoles, de una vez para siempre, la Patria, el Pan y la Justicia"30; la creación de los sindicatos verticales -cuyos jefes deberían ser obligatoriamente militantes del partido-; o los anuncios de "una acción constante y eficaz en defensa del trabajador, su vida y su trabajo limitará convenientemente la duración de la jornada, para que no sea excesiva, y otorgará al trabajo toda suerte de garantías de orden defensivo y humanitario. En especial, prohibirá el trabajo nocturno de las mujeres y niños, regulará el trabajo a domicilio y libertará a la mujer casada del taller y de la fábrica"; el descanso dominical, las vacaciones pagadas, el subsidio familiar y los seguros sociales.

De la misma manera se incluía la creación de las "instituciones necesarias para que en las horas libres y en los recreos de los trabajadores tengan éstos acceso al disfrute de todos los bienes de la cultura, la alegría, la milicia, la salud y el deporte", lo que no era sino una copia de lo que llevaban ya años implementando los regímenes italiano y alemán a través de instituciones como la Opera Narionale Dopolavoroy la Kraft durch Freude. Igualmente se citaba -a inspiración de la Ley del Trabajo Alemán de 1934- la figura del jefe de empresa, responsable ante el Estado de una "unidad productora que ordenará los elementos que la integran en una jerarquía" y fundamental en el control de la mano de obra. Por lo demás, el Fuero prohibía las huelgas, algo que satisfacía a los intereses empresariales y patronales. El papel concedido al jefe de la empresa era más restrictivo que el de la Carta del Lavoro y significaba una limitación a la fascistización que los falangistas perseguían. Por otra parte, el documento reconocía específicamente la propiedad privada, aunque se recalcaba su subordinación al interés nacional representado por el Estado.

El Régimen de Franco acababa de sintetizar sus aspiraciones en el ámbito social, de manera mucho más matizada y mixtificada que en los 26 Puntos del programa del partido, pero dejaba claro que, al menos en la teoría, no pretendía ser simplemente un régimen conservador, cerrado a toda reforma, sino uno que se preocupase por el bienestar de los trabajadores. No incluía la revolución nacionalsindicalista falangista explícitamente, ni los puntos más radicales del programa del partido, pero sí cierta voluntad de reforma. Ello estaba en consonancia con el propio hecho de la guerra, y en la lucha ideológica y propagandista que también se libraba en contra de un enemigo que presentaba a los dirigentes franquistas en tanto grupo no ya represor de los trabajadores sino como anti obrero y al servicio directo de la propiedad. Pero también mostraba la heterogeneidad

\footnotetext{
${ }^{30}$ Preámbulo del Fuero del Trabajo en Legislación del Movimiento, Madrid, Instituto de Estudios Políticos, 1945, pág.
} 11. 
de la coalición autoritaria y el relativo protagonismo que el partido fascista estaba teniendo dentro de él.

Se estaban poniendo las bases de lo que llegaría al finalizar la guerra en los últimos días de marzo de 1939. A partir de ese momento y hasta 1941 el partido se desarrollaría sobre todo el territorio nacional y se dotaría de leyes totalitarizantes que afectarían a la esfera sindical y a la socialización de la juventud y de la mujer al tiempo que adquiriría una gran presencia pública a través de los cuantiosos periódicos, revistas y semanarios incautados a los partidos republicanos e izquierdistas así como mediante la organización de numerosas concentraciones monstruo con las que pretendía demostrar su pujanza y sus aspiraciones de llegar a lograr el poder del Estado. Manteniendo, sí, a Franco en la cima, pero conformando un régimen auténticamente fascista.

Todo ello de la mano de sus dirigentes viejofalangistas amparados ahora por un Serrano Suñer convertido en auténtico número dos de la organización desde su cargo de presidente de la Junta Política. Un Serrano que se había construido una base de poder propia en el partido auspiciando hasta cierto punto los deseos de la cúpula de éste por avanzar irremisiblemente hacia la conquista del Estado. Un Serrano, por ello mismo, cada vez más distanciado de su concuñado, por razones políticas y también personal-familiares. Las aspiraciones falangistas chocaban, en una lucha sorda pero real, con las del resto de sectores de la coalición autoritaria, que eran también diversos pero estaban unidos ante la presencia constante de FET y de las JONS y sus aspiraciones hegemónicas. Destacarían en su oposición el ejército, la iglesia, los monárquicos y los sectores patronales y empresariales. El primero porque se consideraba el verdadero protagonista de la victoria y veía con recelo los avances falangistas. La iglesia, inquieta por las pretensiones totalitarias del partido, que invadía parcelas en las que había estado presente tradicionalmente, como las asociaciones piadosas y activistas de hombres, mujeres y niños. Los carlistas porque no sólo asistían con estupor a la monopolización del partido unificado por Falange sino porque seguían luchando por una monarquía que el Caudillo no estaba instaurando; los alfonsinos por lo mismo, porque no veían a Franco por la labor de restaurar la monarquía en la persona de Alfonso XIII o de su único hijo varón sano, Don Juan de Borbón y Battenberg. Y los sectores empresariales y patronales por el temor que les producían algunas de las posiciones reformistas de los falangistas.

Muchas tensiones juntas, que acabarían estallando en la llamada Crisis de Mayo de 1941 y algo más de un año después con el cese de Serrano Suñer de su cargo ministerial -por entonces y desde octubre de 1940- el de Asuntos Exteriores. Atrás habían quedado también los intentos de Franco, el ejército y el partido por lograr de Hitler la entrada del país en la guerra mundial ${ }^{31}$-al no comprometerse aquel a ceder todos los territorios coloniales que se le reclamaban- y los posteriores enfrentamientos entre falangistas, carlistas y ejército de los Sucesos de Begoña de agostoseptiembre de $1942^{32}$. Todos estos acontecimientos quedan fuera del alcance del presente artículo, pero muestran que la conflictividad interna del bloque político y social franquista fue notable. Lo fue siempre, aunque en grado diverso, hasta el fin del propio régimen en 1977, aunque haya sido largamente descuidada por la historiografía.

\footnotetext{
31 Tusell, Javier, Franco, España y la Segunda Guerra Mundial. Entre el Eje y la neutralidad, Madrid, Temas de hoy, 1995.

32 Thomàs, Joan Maria, Franquistas contra franquistas. Luchas por el poder en la cúpula del régimen de Franco, Barcelona, Debate, 2016.
} 